\title{
Age-Dependent In Vivo Conversion of Mouse Cochlear Pillar and Deiters' Cells to Immature Hair Cells by Atoh1 Ectopic Expression
}

\author{
Zhiyong Liu, ${ }^{1,3}$ Jennifer A. Dearman, ${ }^{1}$ Brandon C. Cox,${ }^{1}$ Brandon J. Walters, ${ }^{1}$ Lingli Zhang, ${ }^{1}$ Olivier Ayrault, ${ }^{2}$ \\ Frederique Zindy, ${ }^{2}$ Lin Gan, ${ }^{4}$ Martine F. Roussel, ${ }^{2}$ and Jian Zuo ${ }^{1}$ \\ Departments of ${ }^{1}$ Developmental Neurobiology and ${ }^{2}$ Tumor Cell Biology, St. Jude Children's Research Hospital, Memphis, Tennessee 38105, ${ }^{3}$ Integrated \\ Program in Biomedical Sciences, University of Tennessee Health Science Center, Memphis, Tennessee 38163, and ${ }^{4}$ Flaum Eye Institute, University of \\ Rochester School of Medicine and Dentistry, Rochester, New York 14642
}

Unlike nonmammalian vertebrates, mammals cannot convert inner ear cochlear supporting cells (SCs) into sensory hair cells (HCs) after damage, thus causing permanent deafness. Here, we achieved in vivo conversion of two SC subtypes, pillar cells (PCs) and Deiters' cells (DCs), into HCs by inducing targeted expression of Atoh1 at neonatal and juvenile ages using novel mouse models. The conversion only occurred in $\sim 10 \%$ of PCs and DCs with ectopic Atoh1 expression and started with reactivation of endogenous Atoh 1 followed by expression of $11 \mathrm{HC}$ and synaptic markers, a process that took approximately 3 weeks in vivo. These new HCs resided in the outer HC region, formed stereocilia, contained mechanoelectrical transduction channels, and survived for $>2$ months in vivo; however, they surprisingly lacked prestin and oncomodulin expression and mature HC morphology. In contrast, adult PCs and DCs no longer responded to ectopic Atoh1 expression, even after outer HC damage. Finally, permanent Atoh1 expression in endogenous HCs did not affect prestin expression but caused cell loss of mature HCs. Together, our results demonstrate that in vivo conversion of PCs and DCs into immature HCs by Atoh1 is age dependent and resembles normal HC development. Therefore, combined expression of Atoh1 with additional factors holds therapeutic promise to convert PCs and DCs into functional HCs in vivo for regenerative purposes.

\section{Introduction}

The auditory sensory epithelium of the cochlea, also known as the organ of Corti, contains one row of inner hair cells (IHCs) and three rows of outer hair cells (OHCs), as well as surrounding supporting cells (SCs), including the two SC subtypes: pillar cells

Received Feb. 20, 2012; revised March 21, 2012; accepted March 21, 2012.

Author contributions:Z.L., J.A.D., B.C.C., M.F.R., and J.Z. designed research;Z.L., J.A.D., B.J.W., L.Z., O.A., and F.Z. performed research; L.G. contributed unpublished reagents/analytic tools; Z.L. and J.A.D. analyzed data; Z.L., B.C.C., M.F.R., and J.Z. wrote the paper.

This work was supported by National Institutes of Health Grants DC06471 (J.Z.), DC05168 (J.Z.), DC008800 (J.Z.), DC010310 (B.C.C.), and CA096832 (M.F.R.), and the Core Grant CA21765; the Office of Naval Research Grant N000140911014 (J.Z.); the American Lebanese Syrian Associated Charities (ALSAC) of St. Jude Children's Research Hospital (Memphis, TN); and travel awards from Academic Programs of St. Jude Children's Research Hospital, University of Tennessee Health Science Center (Memphis, TN), Society of Developmental Biology (Bethesda, MD), and Howard Hughes Medical Institute Janelia Farm Research Campus (Ashburn, VA) (Z.L.). J.Z. is a recipient of The Hartwell Individual Biomedical Research Award. We thank Dr. W. Richardson (University College London, London,

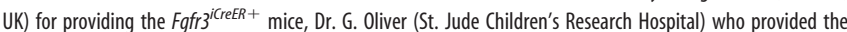
Prox $1^{\text {CreER/+ }}$ mice, Dr. J. Robbins (Cincinnati Children's Hospital, Cincinnati, OH) for the CAG-IoXP-stop-IoxP-EGFP+ reporter mice, and Dr. J. Johnson (University of Texas Southwestern Medical Center, Dallas, TX) for the Atoh1-EGFP+ mice. We thank Dr. T. Jacks (Massachusetts Institute of Technology, Cambridge, MA) for the gift of the CAG promoter and the loxP-STOP-IoxP cassette, and Dr. Dwayne Simmons (University of California, Los Angeles, CA) for the oncomodulin antibody. We appreciate the critical comments of Dr. P. Chen and Dr. M. Kelly (Emory University, Atlanta, $\mathrm{GA}$ ) and those of all members of the Zuo laboratory.

The authors declare no competing financial interests.

Correspondence should be addressed to Dr. Jian Zuo, Department of Developmental Neurobiology, St. Jude Children's Research Hospital, 262 Danny Thomas Place, Memphis, TN 38105. E-mail: jian.zuo@stjude.org.

DOI:10.1523/JNEUROSCI.0818-12.2012

Copyright $\odot 2012$ the authors $\quad 0270-6474 / 12 / 326600-11 \$ 15.00 / 0$
(PCs) and Deiters' cells (DCs), which are directly underneath hair cells (HCs) (see Fig. 1 A). During cochlear development, HCs and SCs are believed to share the same prosensory progenitors (Fekete et al., 1998). Atoh1 is a basic helix-loop-helix transcription factor required for HC development (Chen et al., 2002; Woods et al., 2004); no HCs appear in Atoh1 germline knock-out mice (Bermingham et al., 1999).

When HC damage occurs in nonmammalian vertebrates, including birds and fish, their SCs spontaneously turn on Atoh1, and some change cell fate to become new HCs (Cafaro et al., 2007); however, mammals have lost this capacity and suffer permanent deafness after HC damage (Brigande and Heller, 2009). In vitro ectopic expression of Atoh 1 in the nonsensory greater epithelial ridge (GER) (see Fig. 1A) of neonatal rat cochlear explants generates ectopic HCs (Zheng and Gao, 2000), first suggesting the sufficiency of Atohl in specifying a $\mathrm{HC}$ fate in a permissive cellular environment. In addition, in vivo overexpression of Atoh1 in mouse otocysts by electroporation (Gubbels et al., 2008) and in the adult cochlea of guinea pigs by viral transduction (Izumikawa et al., 2005) also leads to new HCs. However, it is unclear whether various postmitotic mouse SC subtypes, at different postnatal ages, are able to respond to ectopic Atoh1 expression and be converted into HCs. This question is of particular interest for PCs and DCs, given that they lie directly underneath $\mathrm{HCs}$ and that regenerated HCs in birds are derived from the SCs that surround damaged HCs (Stone and Cotanche, 2007). 


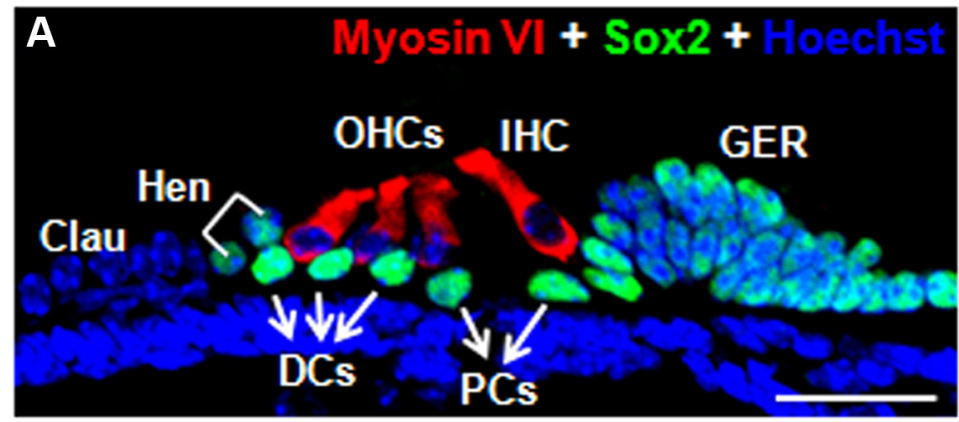

B LoxP sequence

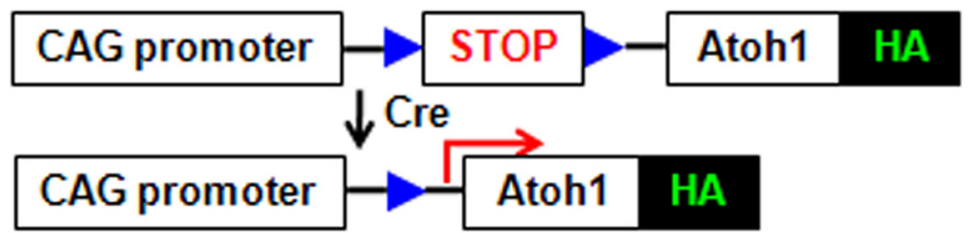

Atoh1-HA + Prestin + Myosin VI

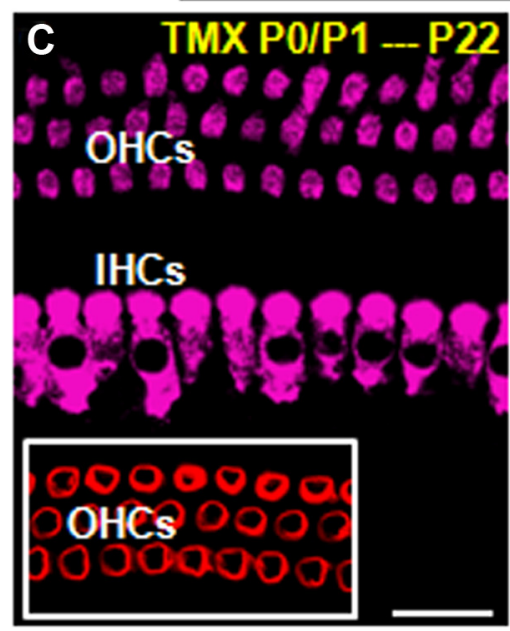

Atoh1-HA+ (Ctrl)

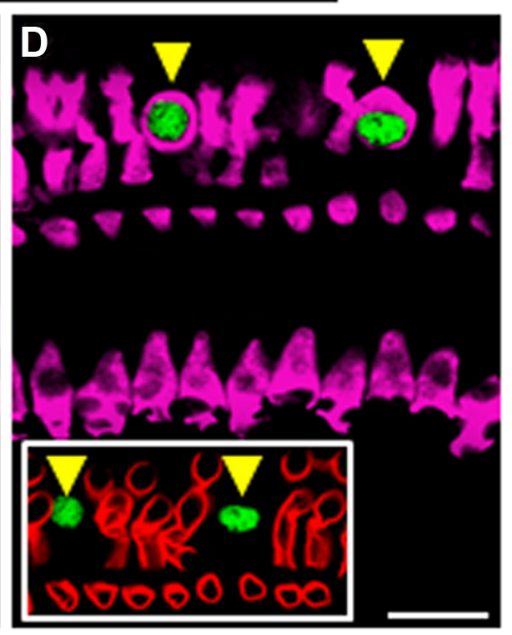

Prox1CreER+; Atoh1-HA+
Figure 1. Reprogramming of neonatal PCs and DCs into HCs by ectopic Atoh1-HA expression in Prox $1^{\mathrm{CreER} /+} ;$ Atoh1-HA + mice. $\boldsymbol{A}$, Cross-section of a P6 wild-type mouse cochlea. HCs are labeled by myosin VI (red), SCs by Sox2 (green), and nuclei by Hoechst (blue). $\boldsymbol{B}$, Illustration of the strategy to induce ectopic Atoh1-HA expression. $\boldsymbol{C}, \boldsymbol{D}$, Mice of the indicated genotypes received tamoxifen (TMX) at P0 and P1 and were analyzed at P22. Triple staining of HA (green), prestin (red), and myosin VI (pink) at P22 in control $(\boldsymbol{C t r l})(\boldsymbol{C})$ and experimental mice $(\boldsymbol{D})$. Arrowheads in $\boldsymbol{D}$ and its inset are the same two newly generated HCs. Hen, Hensen's cells; Clau, Claudius cells. Scale bars: $20 \mu \mathrm{m}$.

Moreover, it is unclear whether ectopic Atoh1 expression alone in SCs is sufficient to promote the complete maturation of new HCs.

Using our newly generated CAG-loxP-stop-loxP-Atoh1-HA transgenic mouse line bred with different SC-specific CreER mouse lines, we found that PCs and DCs from neonatal and juvenile mice can be converted into HCs. Newly generated HCs resided in the $\mathrm{OHC}$ region and survived for more than 2 months but surprisingly lacked expression of oncomodulin and prestin, late and terminal differentiation markers, respectively, for OHCs. They also lacked the morphology of mature OHCs both in cell shape and stereocilia structure. Interestingly, even in the context of OHC damage, such conversion did not occur in adult mice. In addition, permanent Atoh1 expression in endogenous HCs did not affect prestin expression but induced cell loss of mature HCs.
These data demonstrate that neonatal and juvenile PCs and DCs can be converted into immature HCs in vivo by targeted expression of Atoh1, and this potential declines with age. Furthermore, such conversion recapitulates normal $\mathrm{HC}$ development; however, in contrast to common belief, Atoh1 is insufficient to complete the maturation of new HCs and additional factors are required. Our results thus have significant therapeutic implications for human deafness.

\section{Materials and Methods}

Mouse models. CAG-loxP-stop-loxP-Atoh1$H A+$ transgenic mouse lines were generated by the following method. The Atoh1-HA construct was designed by creating primers that attached two hemagglutinin (HA) tags to the $3^{\prime}$ end of the pGEM-T EASY Atoh1 vector. It was then put back into the pGEM-T EASY vector. NotI restriction enzyme was used to cut out the Atoh1-HA-HA (abbreviated as Atoh1-HA hereafter). The vector pCAGGS-S-stop-IRESGFP was also digested with NotI to remove the IRES-GFP. The Atoh1-HA was then ligated into the pCAGGS-S-stop vector. The final size after the backbone was digested out with Sall was $4.8 \mathrm{~kb}$. Proxl ${ }^{\mathrm{CreER} /+}, \mathrm{Fgfr} 3^{\mathrm{iCreER+}}, \mathrm{CAG}^{-}$ loxP-stop-loxP-EGFP+, Rosa26-CAG-loxP-stoploxP-tdTomato, Gfil ${ }^{\mathrm{Cre} /+}, \alpha 9$ AChR-EGFP+, and Atoh1-EGFP+ mice were described previously (Zuo et al., 1999; Chen et al., 2002; Nakamura et al., 2006; Srinivasan et al., 2007; Rivers et al., 2008; Madisen et al., 2010; Yang et al., 2010a; Young et al., 2010). Tamoxifen was injected intraperitoneally (i.p.) once daily at 3 $\mathrm{mg} / 40 \mathrm{~g}$ for neonatal [postnatal days (P) 0 and $\mathrm{P} 1]$ or juvenile mice (P12 and P13) and at 9 $\mathrm{mg} / 40 \mathrm{~g}$ for adult mice (P30 and P33). 5-Ethynyl-2-deoxyuridine (EdU, Invitrogen) was injected i.p. once daily at $10 \mu \mathrm{g} / \mathrm{g}$. Mice of either sex were used for all experiments. The care and use of the mice during the course of this study were approved by the Institutional Animal Care and Use Committee at St. Jude Children's Research Hospital (Memphis, TN).

In vivo OHC damage and FM4-64FX uptake. $\mathrm{OHC}$ damage at adult ages with kanamycin [1000 mg/kg, subcutaneous (s.c.), Sigma] and furosemide (400 mg/kg i.p., Hospira) was performed as described previously (Oesterle et al., 2008). Injection of the red fluorescent FM 4-64FX dye (F34653, Invitrogen) in neonates was described previously (Meyers et al., 2003). To facilitate FM 4-64X dye reaching the cochlea in adults, furosemide (400 $\mathrm{mg} / \mathrm{kg}$, i.p., Hospira) was given $30 \mathrm{~min}$ after FM4-64FX (5 mg/kg, s.c.) injection. FM 4-64FX and furosemide were injected at P59, and samples were analyzed at P60.

Tissue preparation, immunofluorescence, and analysis. Tissue was prepared and examined as described previously (Liu et al., 2010; Yu et al., 2010). All images were taken using confocal microscopy (Zeiss LSM 700). The following primary antibodies were used: anti-myosin VI (1:200, catalog no. 25-6791, Proteus Bioscience), anti-myosin VIIa (1:200, catalog no. 25-6790, Proteus Bioscience), anti-calbindin (1:500, catalog no. AB1778, Millipore), anti-calretinin (1:500, catalog no. AB5054, Millipore), Alexa Fluor 546-conjugated phalloidin (1:100, catalog no. A22283, Invitrogen), anti-parvalbumin (1:2000, catalog no. P3088, Sigma), anti-HA (1:100, catalog no. 11867431001, Roche), anti-prestin 
(1:200, catalog no. sc-22692, Santa Cruz Biotechnology), antioncomodulin (1:200, catalog no. OM3, Swant), anti-KCNQ4 (1:200, catalog no. sc-20882, Santa Cruz Biotechnology), anti-synaptotagmin I (1:50, catalog no. 105011, Synaptic Systems), anti-synaptophysin (1:200, catalog no. 101011, Synaptic Systems), anti-cysteine string protein (CSP) (1:1000, catalog no. AB1576, Millipore), anti-Lhx3 (1:2000, catalog no. AB3202, Millipore), anti-GFP (1:1000, catalog no. ab13970, Abcam), and anti-Sox2 (1:1000, catalog no. sc-17320, Santa Cruz Biotechnology). All secondary antibodies were purchased from Invitrogen and used at a 1:1000 dilution. EdU staining protocol was described previously (Yu et al., 2010).

Quantification of newly generated hair cells. Cochlear samples were cut into three parts. After scanning each part with a confocal microscope using a $10 \times$ lens, the total length of the cochlea was measured. Then, each cochlea was divided into three turns (basal, middle, and apical) with equal length. For the Prox ${ }^{\mathrm{CreER}+} ;$;tohl-HA+ model, because of the limited new HC numbers, each entire cochlea was imaged using a $40 \times$ lens, taking Z-stack images at a $1 \mu \mathrm{m}$ interval. For the $\mathrm{Fgfr}{ }^{i \mathrm{CreER}+}{ }^{+}$A toh 1 $H A+; A$ toh1-EGFP+ model at P15 and P19, all cochlear turns were

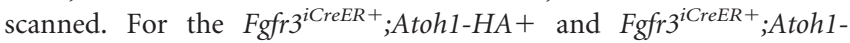
$H A+$;Atoh1-EGFP+ models at P42, because there were plenty of new HCs found with relatively even distribution across cochlear turns, two regions at each basal, middle, and apical turn were randomly chosen and an averaged $\mathrm{HC}$ number was calculated for each sample.

\section{Results}

Generation of mouse lines with inducible expression of Atoh1 Atoh1 is normally undetected in SCs at postnatal ages (Woods et al., 2004; Chow et al., 2006). In the current study, we focused on the SC subtypes PCs and DCs, which are directly underneath endogenous HCs (Fig. 1A), with the belief that they may be a good source for HC regeneration in situ. To express Atoh1 in postnatal PCs and DCs, we generated inducible CAG-loxP-stoploxP-Atoh1-HA (Atoh1-HA) transgenic mouse lines in which Atoh1 (with two hemagglutinin tags at the $\mathrm{C}$ terminus) is driven by the ubiquitous $C A G$ promoter with its expression blocked until the STOP fragment flanked by 2 LoxP sites is deleted in a Cre-mediated manner (Utomo et al., 1999) (Fig. 1B). To confirm that HA-tagged Atoh1 has similar biological activity as untagged Atoh1, granule neuronal progenitors, purified from the cerebella of wild-type mice, were infected with retroviruses expressing Atoh1-HA and Gli1 and orthotopically transplanted into the cortex of CD1-nu/nu recipient mice as reported previously (Ayrault et al., 2010). Medulloblastoma formed with the same time of onset and similar incidence using the Atoh1-HA construct (data not shown) compared to previous reports using untagged Atoh1 (Ayrault et al., 2010). These data demonstrated that the HA tags did not affect the activity of Atoh1.

After pronuclear injection of the transgenic construct, we obtained four independent founders. While all four founders (numbers 10, 11, 12, and 19) ectopically expressed Atoh1-HA in PCs and DCs when crossed with different CreER lines, conversion of PCs and DCs into HCs only occurred in founder number 10 (F10). Therefore, only F10 was used for subsequent analyses.

Ectopic Atoh1-HA converts neonatal pillar and Deiters' cells into immature hair cells

To induce ectopic expression of Atoh1-HA specifically in neonatal PCs and DCs (white arrows in Fig. 1A), we crossed Prox $1^{\mathrm{CreER} /+}$ mice with Atoh1-HA+ mice. Cre activity of Prox $1^{\mathrm{CreER} /+}$ is limited to PCs and DCs when tamoxifen is given at P0 and P1 (Yu et al., 2010).Prox $1^{\mathrm{CreER} /+}$;Atoh1-HA+ mice formed the experimental group and littermate Atoh1-HA+ mice (Cre-negative) were used as the control group, with both groups receiving the same tamoxifen treatment at P0 and P1. We used a HA antibody to

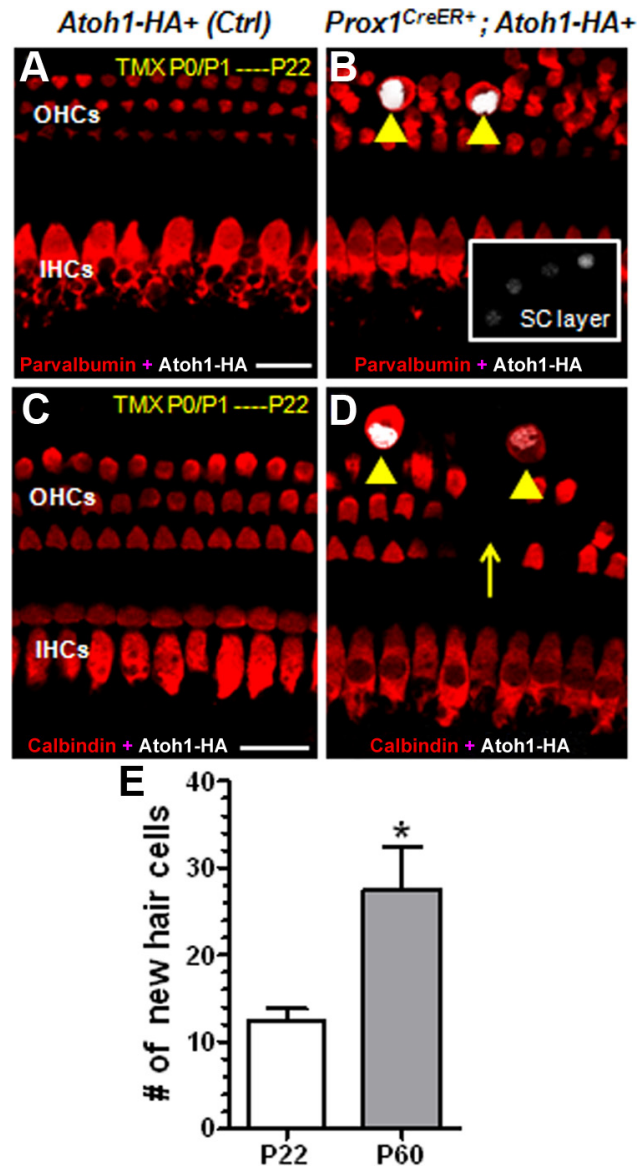

Figure 2. Reactivation of multiple $\mathrm{HC}$ markers in newly generated $\mathrm{HCS} . \boldsymbol{A}, \boldsymbol{B}$, Mice with the indicated genotypes received tamoxifen (TMX) at P0 and P1 and were analyzed at P22. Double labeling of $\mathrm{HA}$ (white) and parvalbumin (red) in control $(\boldsymbol{A})$ and experimental mice $(\boldsymbol{B})$. Arrowheads in $\boldsymbol{B}$ are two new HCs. Inset in $\boldsymbol{B}$ shows Atoh1-HA+/parvalbumin-negative PCs/DCs that remained in the lower SC nuclear layer. Double labeling of $\mathrm{HA}$ (white) and calbindin (red) at P22 in control $(\boldsymbol{C})$ and experimental mice $(\boldsymbol{D})$ is shown. Arrowheads in $\boldsymbol{D}$ are two newly generated $\mathrm{HCs}$. Arrow in $\boldsymbol{D}$ points to the regions where endogenous $\mathrm{OHCs}$ are missing. $E$, Quantification of the new HCs at P22 and P60 in the entire cochlea $\left(^{*} p<0.05\right.$ as determined by a Student's $t$ test). Scale bars, $20 \mu \mathrm{m}$.

visualize ectopic Atoh1-HA expression, which allowed analysis at a single cell resolution. Consistent with the gradient of Cre activity in the different cochlear turns of Prox $1^{\text {CreER/+ }}$ mice (Yu et al., 2010), $\sim 5 \%$ of PCs and $\sim 16 \%$ of DCs were Atoh1-HA + in apical turns, while $\sim 3 \%$ of PCs and $\sim 7 \%$ of DCs were Atoh $1-\mathrm{HA}+$ in middle and basal turns of Prox $1^{\mathrm{CreER} /+}$;Atoh1-HA+ mice at P6 $(n=4)$. We never found Atoh1-HA + cells in control samples. Cre-mediated ectopic expression of Atoh1-HA is permanent (Fig. $1 B$ ), allowing us to perform lineage tracing of Atoh1-HA+ PCs and DCs and to further determine whether they can be converted into $\mathrm{HCs}$ by colabeling with $\mathrm{HA}$ and different $\mathrm{HC}$-specific markers.

We analyzed samples at P6, P12, P22, and P60 in Prox ${ }^{\mathrm{CreER} /+}$; Atoh1-HA + and littermate control mice. P22 was the earliest age at which we found colabeling of HA and myosin VI, HA and parvalbumin, and $\mathrm{HA}$ and calbindin (Figs. $1 C, D, 2 A-D$ ). Myosin VI, calbindin, and parvalbumin are specific markers expressed in HCs, but not in SCs (Avraham et al., 1995; Oesterle et al., 2008; Buckiová and Syka, 2009); thus, we defined cells expressing Atoh1-HA (derived from PCs or DCs) and multiple HC markers as new HCs. Since there were a limited number of new HCs in the Prox ${ }^{\mathrm{CreER} /+}$;Atoh1-HA+ model, we quantified new HCs by 


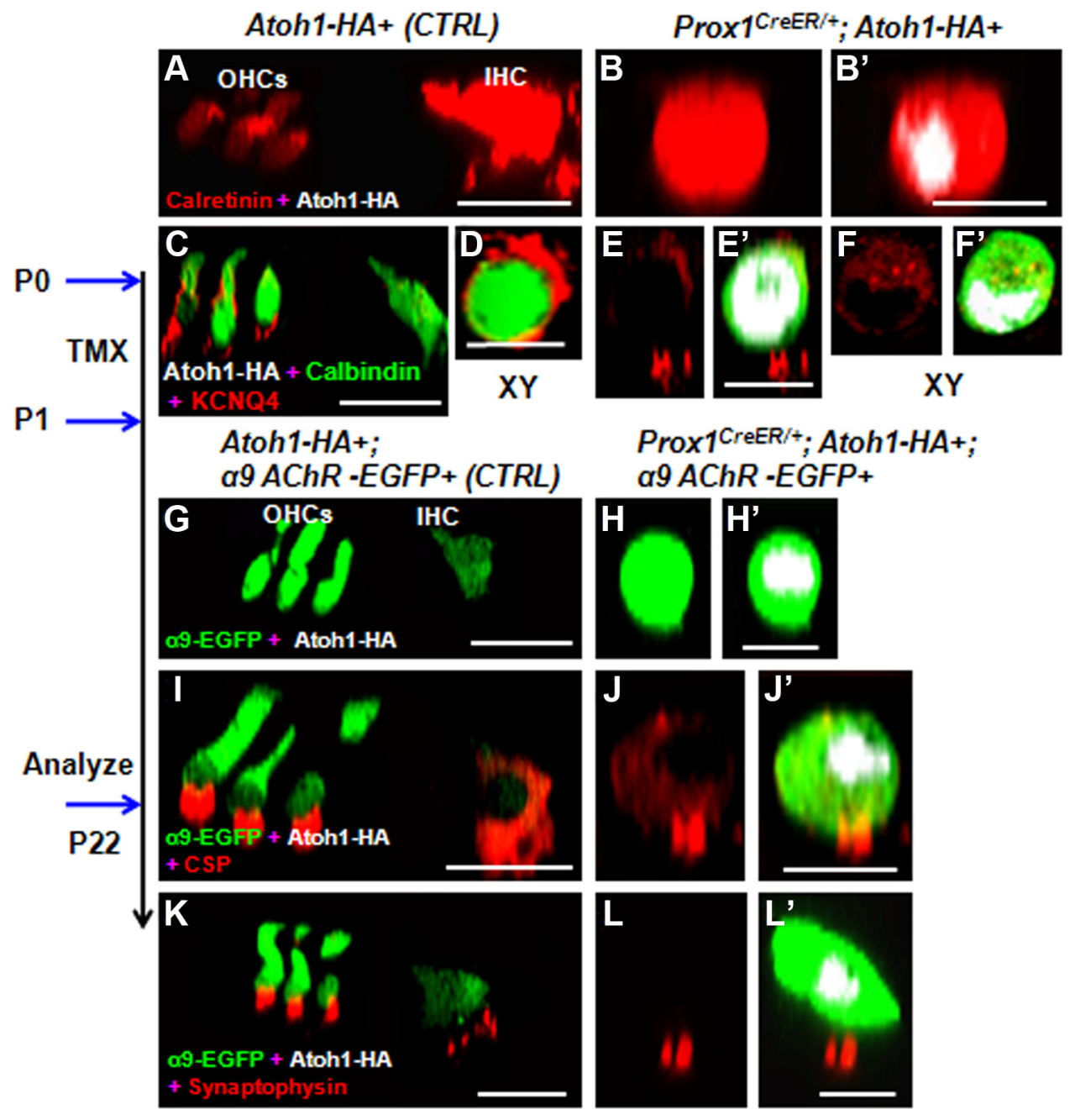

Figure 3. Expression of additional $H C$ and synaptic markers. Mice of the indicated genotypes received tamoxifen (TMX) at PO and P1 and were analyzed at P22. $A, B, D$ ouble staining of HA (white) and calretinin (red) in control $(\boldsymbol{A})$ and experimental $\left(\boldsymbol{B}, \boldsymbol{B}^{\prime}\right)$ mice at P22. $\boldsymbol{B}$ is calretinin alone and $\boldsymbol{B}^{\prime}$ is the merged image. $\boldsymbol{C}-\boldsymbol{F}^{\prime}$, Triple staining of HA (white), calbindin (green), and KCNQ4 (red) in control $(\boldsymbol{C}, \boldsymbol{D})$ and experimental $\left(\boldsymbol{E}-\boldsymbol{F}^{\prime}\right)$ mice at P22. $\boldsymbol{E}$ is KCNQ4 alone and $\boldsymbol{E}^{\prime}$ is the merged image. $\boldsymbol{F}$ is KCNQ4 alone and $\boldsymbol{F}^{\prime}$ is the merged image. $\boldsymbol{E}-\boldsymbol{F}^{\prime}$ show the same cell visualized at confocal $Y-Z$ plane $\left(\boldsymbol{E}, \boldsymbol{E}^{\prime}\right)$ and $X-Y$ plane $\left(\boldsymbol{F}, \boldsymbol{F}^{\prime}\right)$ to better show the KCNQ expression pattern. $\mathbf{G}-\boldsymbol{L}^{\prime}$, Costaining of $\alpha 9$ AChR-EGFP (green) and HA (white) in control $(\boldsymbol{G})$ and experimental $\left(\boldsymbol{H}, \boldsymbol{H}^{\prime}\right)$ mice at P22. $\boldsymbol{H}$ is $\alpha 9$ AChR-EGFP alone and $\boldsymbol{H}^{\prime}$ is the merged image. Triple staining of HA (white), $\alpha 9$ AChR-EGFP (green), and CSP (red) in control $(\boldsymbol{I})$ and experimental $\left(\boldsymbol{J}, \boldsymbol{J}^{\prime}\right)$ mice at P22. $\boldsymbol{J}$ is (SP alone and $\boldsymbol{J}^{\prime}$ is the merged image. Triple staining of HA (white), $\alpha 9$ AChR-EGFP (green), and synaptophysin (red) in control $(\boldsymbol{K})$ and experimental $\left(\boldsymbol{L}, \boldsymbol{L}^{\prime}\right)$ mice at P22 is shown. $\boldsymbol{L}$ is synaptophysin alone and $\boldsymbol{L}^{\prime}$ is the merged image. All images were visualized in the confocal $Y$-Z plane, except $\boldsymbol{D}, \boldsymbol{F}$, and $\boldsymbol{F}^{\prime}$, which were imaged in the $X-Y$ plane. Scale bars: $20 \mu \mathrm{m}(\boldsymbol{A}, \boldsymbol{C}, \boldsymbol{G}, \boldsymbol{I}, \boldsymbol{K}), 10$ $\mu \mathrm{m}\left(\boldsymbol{B}^{\prime}, \boldsymbol{E}^{\prime}, \boldsymbol{H}^{\prime}, \boldsymbol{J}^{\prime}, \boldsymbol{L}^{\prime}\right)$, and $5 \mu \mathrm{m}(\boldsymbol{D})$.

scanning the entire cochlea using confocal microscopy. The number of new HCs per cochlea was much higher at P60 $(27 \pm 5$, $n=4)$ than at P22 $(12 \pm 2, n=3)$, while the total number of Atoh1-HA+ cells per cochlea remained similar (Fig. 2E). This suggests heterogeneity in the reprogramming efficiency among individual Atoh1-HA + PCs and DCs. Note that new HCs (arrowheads in Fig. $2 B$ ) that migrated into the $\mathrm{HC}$ layer had a much higher level of Atoh1-HA expression than the Atoh1-HA+ PCs and DCs that did not express $\mathrm{HC}$ markers and resided in the SC layer (inset in Fig. 2 B). Cell loss of endogenous OHCs adjacent to new HCs was also frequently observed (arrow in Fig. 2D).

To confirm that expression of these three HC markers was due to a global change in gene expression profiles after ectopic expression of Atoh1-HA, we costained HA with five additional HC markers. We found new HCs at P22 that also expressed calretinin (Fig. 3A-B') (Dechesne et al., 1994) and the potassium channel, KCNQ4 (Fig. 3C- $F^{\prime}$ ) (Kubisch et al., 1999). To determine whether the $\alpha 9$ nicotinic acetylcholine receptor ( $\alpha 9 \mathrm{AChR}$ ) was present in new Atoh1-HA+ HCs, we used the $\alpha 9$ AChR-
$\mathrm{EGFP}+$ mouse model where EGFP is driven by the $\alpha 9 \mathrm{AChR}$ promoter (Zuo et al., 1999) and found EGFP+ new HCs in the Prox ${ }^{\text {CreER/+}}$;Atoh1-HA+; $\alpha 9$ AChR-EGFP+ mice at P22 (Fig. $3 G-$ $\left.H^{\prime}\right)$. However, new HCs did not express prestin (inset in Fig. $1 D$ ) and oncomodulin (data not shown), which are late or terminal differentiation markers of OHCs that are turned on in wild-type OHCs after P2 (Legendre et al., 2008; Simmons et al., 2010). In addition, we found evidence of three synaptic markers, CSP (Fig. 3I-J') (Eybalin et al., 2002), synaptophysin (Fig. 3K-L') (Mustapha et al., 2009), and synaptotagmin1 (data not shown) (Beurg et al., 2010) at the basal regions of new Atoh1-HA+ HCs, which indicates synapse formation between new HCs and neuronal fibers. These results provide strong evidence that ectopic Atoh1 converts PCs and DCs into partially reprogrammed or immature new HCs.

Triple staining of parvalbumin, HA, and actin showed that some new HCs had intense actin staining at their apical surfaces (Fig. $4 A-A^{\prime \prime}$ ). Consistent with this intense actin staining, $\sim 10 \%$ of new HCs and the remaining endogenous HCs, but not neighboring SCs, took up FM4-64FX dye in vivo (Fig. $4 B-B^{\prime \prime \prime}$ ), which 
occurs through the mechanoelectrical transduction (MET) channels found at the top of HC stereocilia bundles. These data suggest that some new HCs form actin-enriched stereocilia and have MET channels, features that resemble endogenous HCs. In addition, among the total number of Atoh1-HA + PCs and DCs at P60, only $6 \pm 2 \%(n=4)$ were converted into HCs; the remaining $94 \%$ maintained PC/DC cell fate (Fig. 4C). Among the new $\mathrm{HCs}$ at $\mathrm{P} 60, \sim 86.5 \%$ of them maintained the SC marker, Sox2 (Hume et al., 2007), while $\sim 13.5 \%$ were Sox2-negative (Fig. $4 C)$. Interestingly, we have shown that Sox 2 might not affect the differentiation of HCs (Liu et al., 2012). At P60, none of the new HCs in the $\mathrm{OHC}$ region expressed oncomodulin or prestin (data not shown). They also lacked the morphology and polarity of wild-type HCs (Figs. 1C,D, $2 A-D)$, suggesting that new $\mathrm{HCs}$ derived from Atoh1-HA+ PCs and DCs remain immature and not fully differentiated at 2 months.

Juvenile pillar and Deiters' cells can be converted into immature hair cells by ectopic expression of Atoh1-HA

We next determined whether juvenile (i.e., P12-13) PCs and DCs that are in the process of terminal differentiation can still respond to ectopic Atoh1-HA expression and be converted into HCs. Since Prox1 rapidly declines after birth in mouse SCs (BerminghamMcDonogh et al., 2006), Prox $1^{\mathrm{CreER} /+}$ cannot be used to drive ectopic Atoh1-HA expression at juvenile ages; therefore, we used another inducible transgenic mouse line, $\mathrm{Fgfr} 3^{i \mathrm{CreER}+}$ (Rivers et al., 2008; Young et al., 2010). When tamoxifen was given to Fgfr $3^{\text {iCreER+ }}$;CAG-loxP-stop-loxP-EGFP+ reporter mice at P12 and P13, the majority (96\%) of EGFP + cells were PCs and DCs, $2 \%$ were Hensen's and Claudius cells (other SC subtypes outside the organ of Corti; Fig. 1A), and 2\% were OHCs (primarily in apical turns) at P21 (Fig. 5A-E). Among all PCs and DCs, about 93\% were EGFP+ at P21, and there was no difference in Cre activity among cochlear turns.

We analyzed $\mathrm{Fgfr} 3^{i \mathrm{CreER}+}$;Atoh1-HA+ mice as the experimental group and Atoh1-HA+ (Cre-negative) littermate mice as the control group; both were injected with tamoxifen at P12 and P13 and analyzed at P42. In the control mice, we did not find newly generated $\mathrm{HCs}$ or endogenous $\mathrm{OHC}$ loss (Fig. $\left.5 F-F^{\prime \prime \prime}\right)$. In Fgfr $3^{i C r e E R+}$;Atoh1-HA+ mice, we observed $80 \pm 5 \%(n=3)$ of PCs and DCs that were Atoh1-HA+. In an averaged $160 \mu \mathrm{m}$ cochlear length, $11 \pm 2(n=4)$ Atoh1-HA+/calbindin + cells (defined as new HCs) migrated into the HC layer, resided in the $\mathrm{OHC}$ region, and did not express oncomodulin (data not shown) or prestin at P42 (Fig. 5G-G'"). This number of new HCs represents $11.7 \pm 1.9 \%(n=4)$ of the total Atoh1-HA+ PCs and DCs observed at the same age. Additionally, new HCs also expressed parvalbumin and Lhx3, another transcription factor expressed during HC differentiation (Hertzano et al., 2007; Hume et al., 2007; Huang et al., 2008) (Fig. 5H- $H^{\prime \prime \prime}$ ). Atoh1-HA+ PCs and DCs that did not express HC markers remained in the SC layer (inset in Fig. 5G) and could not be visualized in the single confocal slice images taken at the HC layer (Fig. 5G,H). Although some new HCs seemed to be multinucleated (Fig. $5 H^{\prime \prime \prime}$ ), none were EdU+ when $\mathrm{Fg} f \mathrm{r}{ }^{\text {iCreER+}}{ }^{+}$Atoh1-HA+ mice were given EdU at P22, P24, P26, P28, and P30. Finally, cell loss of endogenous OHCs was frequently observed at P42 (Fig. 5G- $H^{\prime \prime \prime}$ ).

\section{Ectopic Atoh1-HA expression cannot convert adult PCs and} DCs into immature HCs

We next determined whether ectopic Atoh1-HA expression could convert fully differentiated adult PCs and DCs into HCs. When tamoxifen was given to $\mathrm{Fgfr}^{\mathrm{iCreER}+}$;Rosa26-CAG-loxPstop-loxP-tdTomato mice $(n=3)$ once at adult ages $(\mathrm{P} 30)$ and analyzed at P39, 92\% of tdTomato + cells were PCs and DCs, and $8 \%$ were Hensen's and Claudius cells (Fig. 6A-E). Note that tdTomato + OHCs were never observed (Fig. 6E). When Fgfr $3^{i C r e E R+}$;Atoh1-HA+ mice were treated with tamoxifen once at P30, $\sim 90 \%$ of PCs and $\sim 50 \%$ of DCs were Atoh1-HA+ at P60. Surprisingly, we no longer observed Atoh1-HA+/calbindin+ $\mathrm{HCs}$ or endogenous $\mathrm{OHC}$ loss (Fig. $6 F, G$ ). We further analyzed mice at P90 and P120 to allow Atoh1-HA+ PCs and DCs to have a longer amount of time to respond to Atoh1-HA expression. Again, no new HCs were found (data not shown). Consistently, $100 \%$ of Atoh1-HA+ PCs and DCs remained in the SC layer and maintained expression of the SC marker, Sox2 (Fig. $6 H-H^{\prime \prime}$ ).

We next speculated that $\mathrm{OHC}$ damage before Atoh1-HA induction might promote adult PCs and DCs to respond to ectopic Atoh1-HA expression. Adult OHCs were first damaged at P30 using a single dose of kanamycin and furosemide (Oesterle et al., 2008). OHC damage was confirmed by auditory brainstem response (ABR) tests at P33 $(n=3)$ (data not shown), followed by tamoxifen injection once at P33 and analysis at P63 (Fig. 6I-K) or P83. While almost all endogenous OHCs were lost (Fig. 6I,J) 

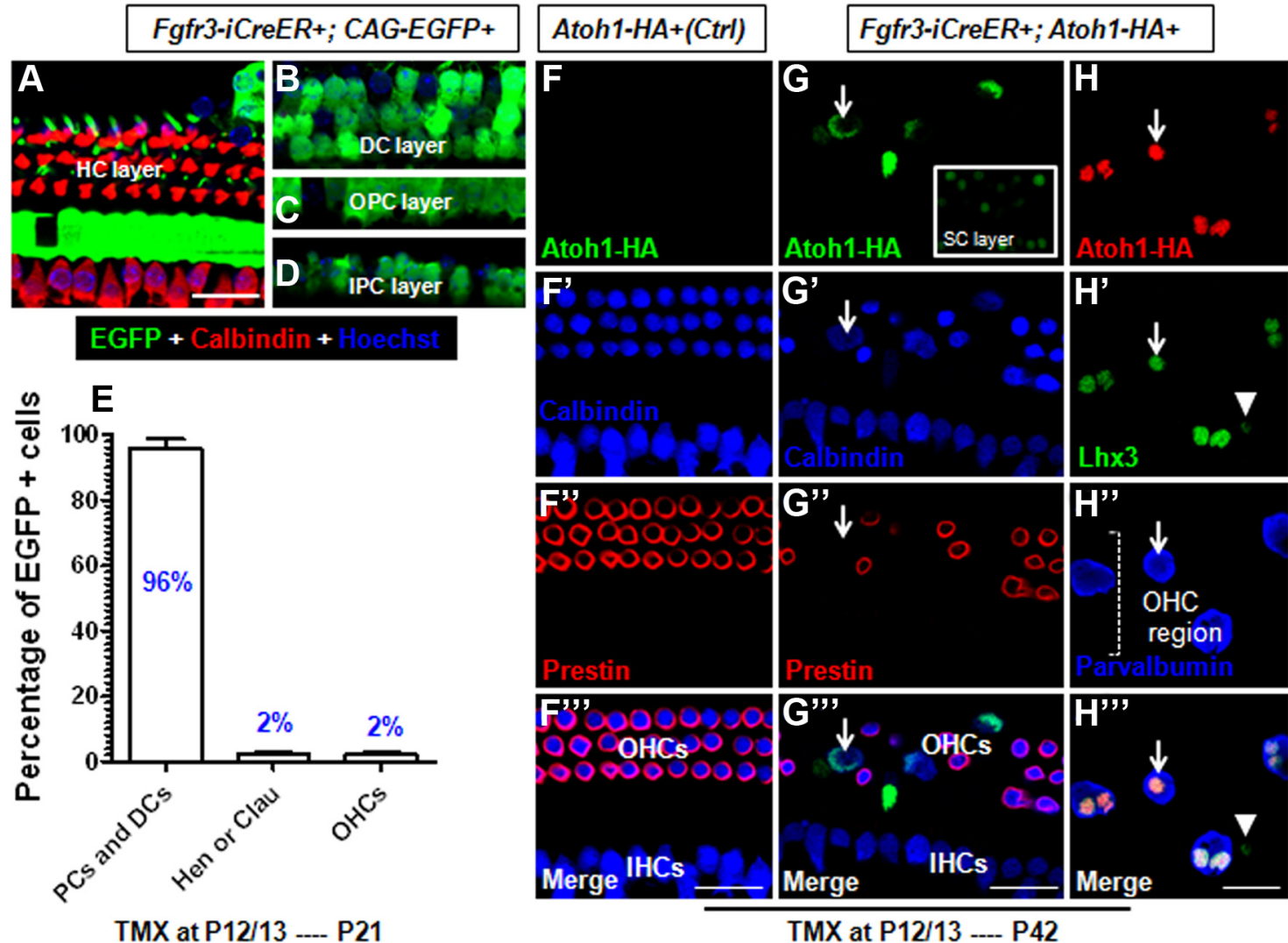

TMX at P12/13 -.- P42

Figure 5. Ectopic Atoh1-HA expression reprogrammed juvenile PCS and DCs into HCS. Mice of the indicated genotypes received tamoxifen (TMX) at P12 and P13 and were analyzed at P21 (A-E) or P42

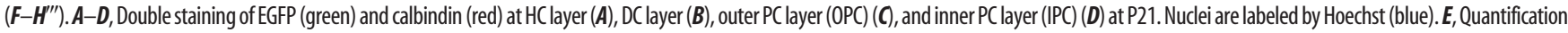
of EGFP+ cells among different cell types. Data are presented as mean \pm SEM. $\boldsymbol{F}-\boldsymbol{G}^{\prime \prime \prime}$, Triple staining of HA (green), calbindin (blue), and prestin (red) in control (F-- $\left.\boldsymbol{F}^{\prime \prime}\right)$ and experimental $\left(\mathbf{G}-\boldsymbol{G}^{\prime \prime \prime}\right)$ mice at P42. Arrows in G-G'" point to one new HC. Inset in G shows Atoh1-HA + PCs and DCs that maintain the SC fate and reside at the SC layer. Many endogenous prestin $+0 \mathrm{OHCs}$ are missing in experimental mice, while IHCs were normal $\left(\mathbf{G}-\boldsymbol{G}^{\prime}\right)$. $\boldsymbol{H}-\boldsymbol{H}^{\prime \prime \prime}$, Triple staining of HA (red), Lhx3 (green), and parvalbumin (blue) in experimental mice at P42. Arrows in $\boldsymbol{H}-\boldsymbol{H}^{\prime \prime \prime}$ point to one new $\boldsymbol{H C}$. Arrowheads in $\boldsymbol{H}^{\prime}$ and $\boldsymbol{H}^{\prime \prime \prime}$ point to one endogenous Lhx3 + HC. Note that the endogenous HCs have parvalbumin expression, but it is expressed at a much lower level than in new HCs. Scale bars, $20 \mu \mathrm{m}$.

and $\sim 90 \%$ of PCs and $\sim 50 \%$ of DCs were Atoh1-HA + in the SC layer (Fig. $6 \mathrm{~K}$ ), we did not find any new HCs, and hearing impairment caused by drug damage was not improved when mice were analyzed by $\mathrm{ABR}$ at $\mathrm{P} 63$ or $\mathrm{P} 83$ (data not shown). We also tried tamoxifen injection at P30 $(n=3)$ and performed drug damage $3 \mathrm{~d}$ later (P33) to allow adult PCs and DCs to express Atoh1-HA before OHC damage. Again, no new HCs were found, and there was no improvement in hearing (data not shown). Therefore, we conclude that ectopic Atoh1 expression cannot convert adult PCs and DCs into immature HCs.

Activation of the endogenous Atoh1 precedes differentiation of new HCs

Studies in other tissues support the notion that endogenous master cell fate determination genes need to be turned on for efficient reprogramming (Xie et al., 2004; Zhou et al., 2008; Szabo et al., 2010 ). Because $\sim 80 \%$ of PCs and DCs had ectopic Atoh1-HA expression and only $\sim 11 \%$ of Atoh1-HA+ DCs and PCs (at juvenile ages) were converted into new HCs in the $\mathrm{Fg} f r 3^{i \mathrm{CreER}+}$; Atoh1-HA+ model (Fig. 5), we performed a more detailed analysis of this model. To determine whether ectopic Atohl-HA can turn on endogenous Atohl in new HCs, Fgfr $3^{i \text { CreER+ }}$;Atoh1-HA+ mice were bred with transgenic Atoh1-EGFP+ mice where EGFP is driven by the Atohl enhancer (Chen et al., 2002). In

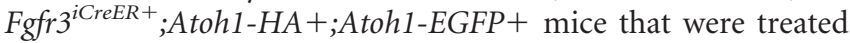
with tamoxifen at P12 and P13, EGFP was used to reflect the activation of endogenous Atoh 1 due to the positive autoregula- tion feedback of Atoh1 (Helms et al., 2000). EGFP expression was visualized in endogenous HCs and inner phalangeal cells (IPHs, another SC subtype), but not in PCs and DCs in Fgfr $3^{i C r e E R+}$; Atoh1-EGFP+ control littermates (Fig. 7A- $\left.\mathrm{A}^{\prime \prime \prime}\right)$. Interestingly, EGFP+/Atoh1-HA+ PCs appeared in Fgfr $3^{\text {iCreER+ }}{ }^{\text {; Atohl-HA+; }}$ Atoh1-EGFP + mice at P15; however, they did not express calbindin and resided in the SC layer (Fig. $7 B-B^{\prime \prime \prime}$ ). At P19, the number of EGFP+/Atoh1-HA + cells increased significantly, but they still were calbindin-negative (Fig. $\left.8 A-B^{\prime \prime \prime}\right)$. At P42, we observed new EGFP+/Atoh1-HA+/calbindin $+\mathrm{HCs}$ in $\mathrm{Fgfr}^{i{ }^{i \mathrm{CreER}+}}$;Atoh1$H A+;$ Atohl-EGFP+ mice (Fig. $\left.8 C-D^{\prime \prime \prime}\right)$. Interestingly, all Atoh1$\mathrm{HA}+/$ calbindin + new HCs also expressed EGFP and all Atoh1$\mathrm{HA}+/ \mathrm{EGFP}+$ cells also expressed calbindin (arrowheads in Fig. $\left.8 D-D^{\prime \prime \prime}\right)$; however, Atoh1-HA+ cells without EGFP expression did not express calbindin (arrows in Fig. $8 D-D^{\prime \prime \prime}$ ). Note that endogenous HCs and IPHs maintained EGFP expression at P42, but the level was much lower than that in new HCs. Together, our data suggest that new HCs follow the normal HC developmental program, where endogenous Atoh1 turns on first followed by expression of other HC markers.

\section{Permanent expression of Atoh1-HA in differentiating} endogenous hair cells does not repress initiation of prestin expression but causes subsequent cell loss

In the above models, ectopic Atoh1-HA expression is induced by Cre-mediated excision of a floxed stop sequence and thus is permanent. We found that PC- and DC-derived HCs were not fully 

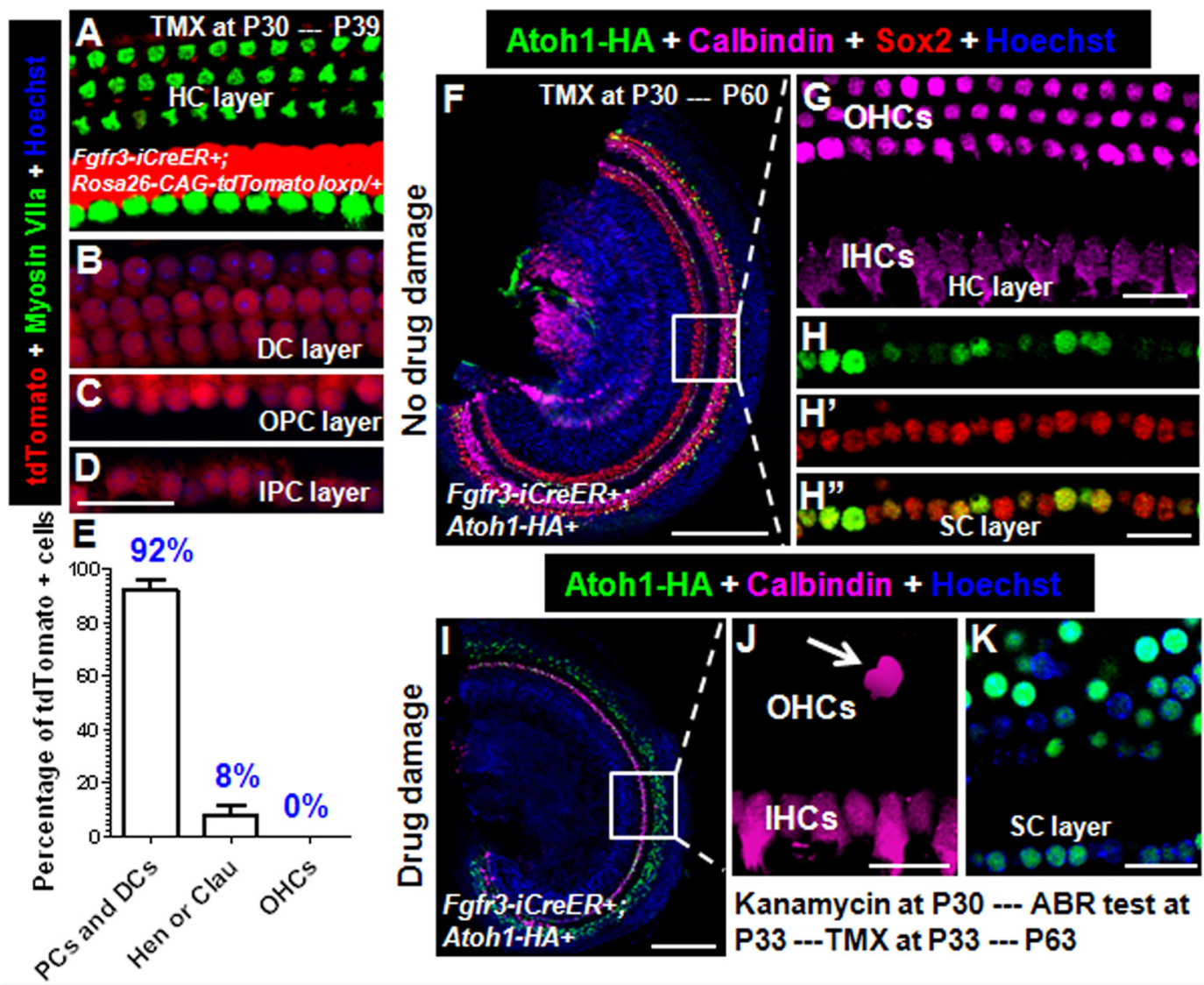

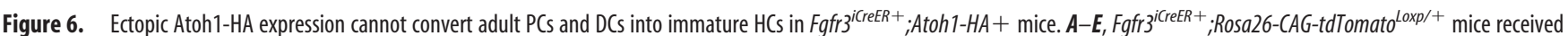
tamoxifen (TMX) at P30 and were analyzed at P39. Double staining of tdTomato (endogenous epifluorescence; red) and myosin Vlla (green) at the HC layer ( $\boldsymbol{A}), \mathrm{DC}$ layer (B), outer PC layer (OPC) (C), and inner PC (IPC) layer (D) at P39. E, Quantification of tdTomato + cells among different cell types. $\boldsymbol{F}-\boldsymbol{H}^{\prime \prime}, F_{\text {ffrr }}{ }^{\text {icreeR+ }}{ }^{;}$;Atoh1-HA + mice were injected with tamoxifen (TMX) at P30 and analyzed at P60. $F$, Low-magnification cochlear whole mount image with triple staining of HA (green), calbindin (pink), and Sox2 (red) in experimental mice at P60. High-magnification images of the square area in $(\boldsymbol{F})$ at the $\mathrm{HC}$ layer $(\boldsymbol{G})$ and $\mathrm{SC}$ nuclear layer $\left(\boldsymbol{H}, \boldsymbol{H}^{\prime \prime}\right)$ are shown. Neither $\mathrm{OHC}$ loss nor new HCs were found in the $\mathrm{HC}$ layer $(\boldsymbol{G})$. Using inner PCs as an example, all Atoh1-HA+ cells expressed Sox2 and remained in the SC layer $\left(\boldsymbol{H}-\boldsymbol{H}^{\prime \prime}\right) . \boldsymbol{I}-\boldsymbol{K}, \mathrm{Fgfr} 3^{\text {icreER+ }}$;Atoh1-HA+ mice were injected with kanamycin at P30 and TMX at P33 and analyzed at P63.I, Low-magnification cochlear whole mount image double stained of $\mathrm{HA}$ (green) and calbindin (pink) after $\mathrm{OHC}$ damage in experimental mice at P63. High-magnification images of the square area in I taken at the $\mathrm{HClayer}(J)$ and the $S \mathrm{C}$ nuclear layer $(\boldsymbol{K})$. Arrow in J labels a single OHC that remained. All Atoh1-HA+ PCs and DCs were found in the SC layer $(\boldsymbol{K})$ and did not express calbindin. Scale bars: $200 \mu \mathrm{m}(\boldsymbol{A}, \boldsymbol{D}) ; 20 \mu \mathrm{m}\left(\boldsymbol{B}, \boldsymbol{C}^{\prime \prime}, \boldsymbol{E}, \boldsymbol{F}\right)$.
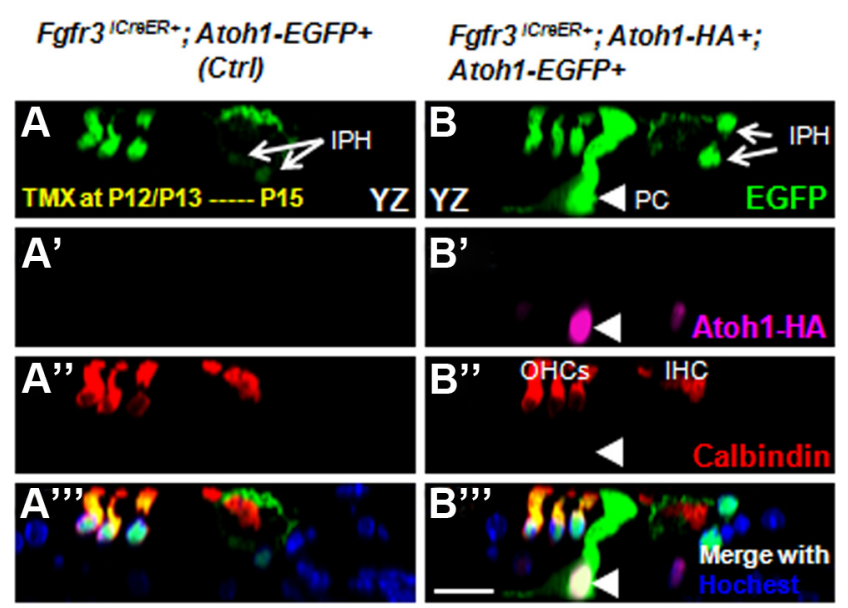

Figure 7. Reactivation of endogenous Atoh1 in Atoh1-HA+ cells. $\boldsymbol{A}-\boldsymbol{B}^{\prime}$, Mice of the indicated genotypes received tamoxifen (TMX) at P12 and P13 and were analyzed at P15. Images taken from cochlear samples stained with EGFP (green), HA (pink), and calbindin (red) in control $\left(\boldsymbol{A}-\boldsymbol{A}^{\prime \prime \prime}\right)$ and experimental $\left(\boldsymbol{B}-\boldsymbol{B}^{\prime \prime \prime}\right)$ mice at P15 are visualized in the confocal $Y-Z$ plane. Arrowheads $\left(\boldsymbol{B}-\boldsymbol{B}^{\prime \prime \prime}\right)$ label the same Atoh1-HA+/EGFP + PC that was calbindin negative, and its nucleus resided at the bottom of the cell body. Arrows in $\boldsymbol{A}$ and $\boldsymbol{B}$ are IPHs with EGFP expression in both the control and experimental group. The endogenous HCs were also EGFP + . Scale bar, $20 \mu \mathrm{m}$. differentiated, even though multiple HC-specific genes were expressed. This could be caused by the lack of additional unknown factors that are needed to fully convert PCs and DCs into mature HCs or by permanent Atoh1 expression that prevents new HCs from completing terminal differentiation. While the former scenario remains attractive to be explored in the future, we tested the latter using a HC-specific Cre to permanently express Atoh1-HA in developing, endogenous HCs. With the assumption that embryonic differentiating endogenous HCs are similar to PC/DC-derived new HCs, we used the Gfi1 ${ }^{\mathrm{Cre} /+}$ mouse model to express Atoh1-HA in developing HCs. Inside the organ of Corti, Cre activity in $\mathrm{Gfil}^{\mathrm{Cre} /+}$ mice starts at embryonic day (E) 15.5 and is specific to HCs (Yang et al., 2010a); thus, in $\mathrm{Gfil}^{\mathrm{Cre} /+}$; Atoh1-HA+ mice differentiating, endogenous HCs around E16 or E16.5 should start to have both endogenous Atoh1 and ectopic Atoh1-HA expression in a basal to apical gradient.

We analyzed cochlear samples of $\mathrm{Gfi1}^{\mathrm{Cre} /+}$; Atoh1-HA+ mice at P3, P14, and P35. Almost all HCs were Atoh1-HA+/myosin $\mathrm{VI}+$ and looked normal at P3 $(n=3)$ (Fig. $\left.9 A-A^{\prime \prime \prime}\right)$; however, at P14 $\sim 60 \%$ of HCs were lost in the basal turn $(n=3)$, while middle and apical HCs were normal (Fig. 9B,D) except for the most apical region, where varied $\mathrm{OHC}$ loss was present. The remaining IHCs were Atoh1-HA+/calbindin+, and OHCs were Atoh1-HA+/calbindin+/prestin + (Fig. 9C-C'", $\left.E-E^{\prime \prime \prime}\right)$. When 


\section{Atoh1-HA + EGFP + Calbindin +}
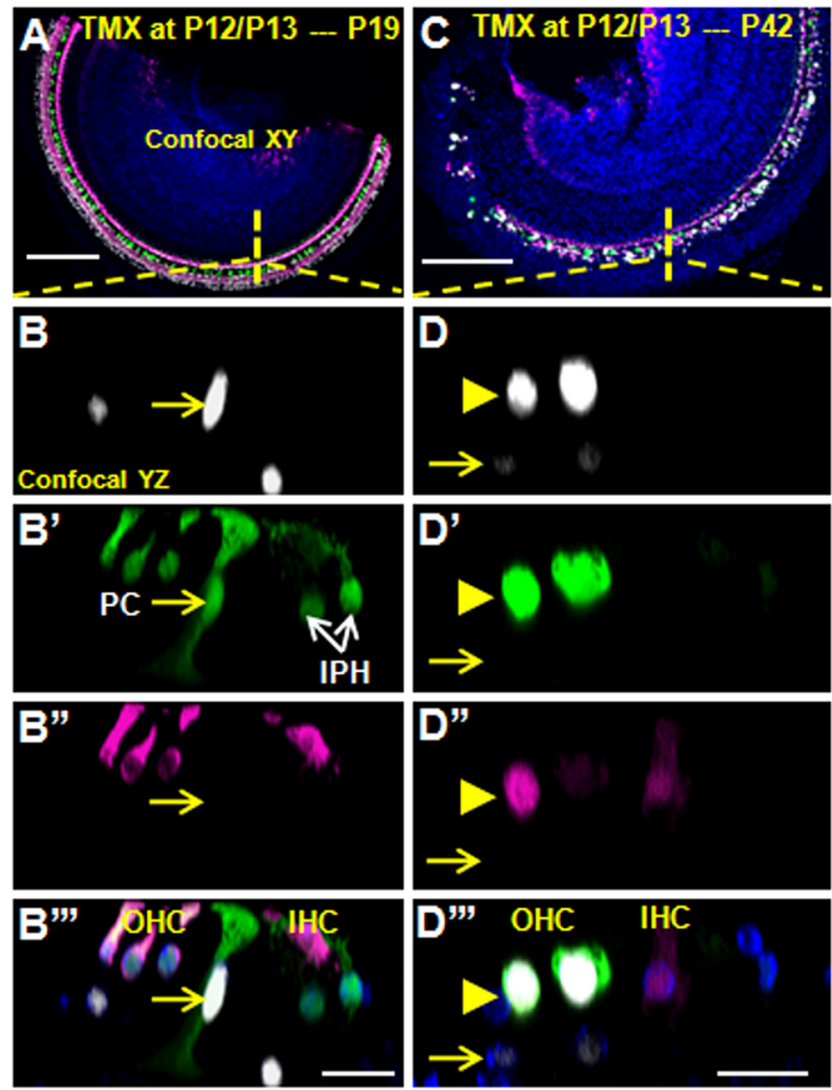

Figure 8. Reactivation of endogenous Atoh1 precedes differentiation of new HCs in $\mathrm{Fgfr}^{\text {iCreER }}{ }^{+}$;Atoh1-HA+;Atoh1-EGFP+ mice. A-D'" ${ }^{\prime \prime}$ Fgfr $^{\text {iCreER }}{ }^{+}$;Atoh1-HA+;Atoh1-EGFP+ mice received tamoxifen (TMX) at P12 and P13 and were analyzed at P19 $\left(\boldsymbol{A}-\boldsymbol{B}^{\prime \prime \prime}\right)$ and P42 $\left(\boldsymbol{C}-\boldsymbol{D}^{\prime \prime \prime}\right)$. Triple staining of HA (white), EGFP (green), and calbindin (pink). $\boldsymbol{B}-\boldsymbol{B}^{\prime \prime \prime}$, Images were visualized at the confocal $Y-Z$ plane through the vertical yellow dashed line in $\boldsymbol{A}$. Yellow arrows point to an Atoh1-HA + /EGFP + PC that did not turn on calbindin, and its nucleus was migrating into the HC layer. White arrows pointed to endogenous IPH cells. $\mathbf{D}-\mathbf{D}^{\prime \prime \prime}$, Images were visualized at the confocal $Y-Z$ plane through the vertical yellow dashed line in $C$. Arrowheads point to an Atoh1-HA +/EGFP +/calbindin + new HC. Arrows point to an Atoh1-HA+/EGFPnegative/calbindin-negative cell (with low level of Atoh1-HA expression). Scale bars: $200 \mu \mathrm{m}$ $(\boldsymbol{A}, \boldsymbol{C}) ; 20 \mu \mathrm{m}\left(\boldsymbol{B}-\boldsymbol{B}^{\prime \prime \prime}, \boldsymbol{D}-\boldsymbol{D}^{\prime \prime \prime}\right)$.

cochlear samples were analyzed at P35 $(n=5), \sim 98 \%$ of HCs in the middle or basal turns and $\sim 85 \%$ of HCs in the apical turn were lost (Fig. $10 \mathrm{~A}, \mathrm{~B}$ ). Consistently, $\mathrm{Gfil}^{\mathrm{Cre} /+}$;Atoh1-HA+ mice were deaf at P35 by ABR test (Fig. 10C). This novel finding indicates that permanent Atoh1-HA expression is not ideal for HC regeneration and that mature, but not immature, HCs are vulnerable to permanent Atoh1-HA expression. We can also conclude that permanent Atoh1-HA expression was not the main cause for the absence of prestin expression in PC/DC-derived HCs; however, we cannot rule out the possibility that PC/DCderived HCs may not follow the same developmental program of endogenous HCs.

\section{Discussion}

We have achieved inducible, ectopic Atoh1-HA expression specifically in two subtypes of postnatal cochlear SCs, PCs and DCs, that reside directly underneath HCs within the organ of Corti. A fraction (6-11\%) of neonatal and juvenile Atoh1-HA+ PCs and DCs were converted into HCs that first activated endogenous Atoh1 and subsequently expressed $11 \mathrm{HC}$ and synaptic markers (myosin VI, myosin VIIa, calbindin, parvalbumin, calretinin, Lhx3, KCNQ4, $\alpha 9$ AChR, synaptogamin1, synaptophysin, and CSP), migrated up into the HC layer, formed stereocilia, had MET channels, and survived for at least 2 months in vivo. However, newly generated HCs lacked oncomodulin and prestin expression and the morphology of mature OHCs (cylinder cell body shape and characteristic "V" shaped stereocilia) and likely remained at an intermediate or immature differentiation stage. In contrast, ectopic Atoh1-HA expression cannot convert adult $\mathrm{PCs}$ and DCs into immature HCs even after endogenous $\mathrm{OHC}$ damage. We also found that permanent Atoh1 expression did not block initiation of prestin expression in endogenous HCs but somehow subsequently resulted in cell loss of both IHCs and OHCs. Taken together, our data suggest that a combination of Atoh1 expression with other factors is needed to convert PCs and DCs (especially at adult ages) into fully differentiated, functional HCs.

Because Cre activity is $100 \%$ specific to PCs and DCs within the organ of Corti in the Prox ${ }^{\mathrm{CreER}+}$;Atoh1-HA+ model, we could confirm, at single cell resolution, that these converted new HCs were derived from PCs and DCs by using Atoh1-HA expression as a lineage tracer. However, at juvenile ages, the Cre activity of $F g f r 3^{i C r e E R}$ is not $100 \%$ specific to PCs and DCs, with $2 \%$ of Cre activity in $\mathrm{OHCs}$ (primarily in apical turns); therefore, it remains possible, albeit very unlikely that a few Atoh1-HA+/calbindin+ new HCs might be endogenous OHCs. We believe that the majority of Atoh1-HA+/calbindin + new HCs are derived from PCs and DCs based on prestin expression and quantitative analysis. Specifically, new HCs derived from PCs and DCs never expressed oncomodulin or prestin (Figs. $1 D, 5 G-G^{\prime \prime \prime}$ ), whereas endogenous OHCs with permanent Atoh1-HA expression expressed prestin (Fig. 9). Therefore, these Atoh1-HA+/calbindin+/prestinnegative $\mathrm{HCs}$ in $\mathrm{OHC}$ regions of $\mathrm{Fgfr}^{\mathrm{iCreER+}}$;Atoh1-HA+ mice are derived from PCs or DCs. In addition, quantitatively in each 160 $\mu \mathrm{m}$ cochlear length, the number $(11 \pm 2, n=4)$ of Atoh1-HA+/ calbindin + cells was much higher than that of OHCs $(1 \pm 1, n=3)$ traced by reporter gene EGFP in the $\mathrm{Fg}_{\mathrm{fr}} \mathrm{3}^{\mathrm{iCreER}+}$;CAG-loxP-stoploxP-EGFP+ mice. Cre activity of $F g f r 3^{i C r e E R+}$ was also detected in a very small fraction of Hensen's and Claudius cells (Fig. $5 E$ ). When we defined and quantified new HCs, Atoh1-HA+/calbindin + cells in regions where Hensen's and Claudius cells are located (Fig. 1A) were not included.

Although Atoh1 is required for HC fate commitment and possibly the differentiation process (Bermingham et al., 1999; Pan et al., 2011), not all Atoh1-expressing cochlear progenitors develop into HCs (Woods et al., 2004; Matei et al., 2005; Yang et al., 2010b), and Atoh1-null HCs can be formed in the mosaic Atoh1 deletion model (Du et al., 2007). Here, we also noticed heterogeneity among SCs that express Atoh1-HA, since the majority (89-94\%) of Atoh1-HA + SCs remained as SCs. Using the Atoh1-EGFP+ transgenic line, we showed that the Atoh1 enhancer region (or the endogenous Atoh1 gene) must be reactivated for a SC to become a HC. Within the organ of Corti, we saw that only those Atoh1-HA+ SCs that activated the Atoh1 enhancer became new HCs, while the rest maintained their original SC fate. In the future it will be interesting to investigate this heterogeneity at the single cell level. Such studies may provide the key for unraveling the long-standing mystery of how Atoh1 dictates cell fate determination (Pan et al., 2012).

Atoh1 is believed to be maximally expressed at embryonic ages and declines rapidly within the first week after birth when $\mathrm{HC}$ maturation is far from completion (Woods et al., 2004; Chow et al., 2006), suggesting that Atoh1 is primarily required for $\mathrm{HC}$ fate 


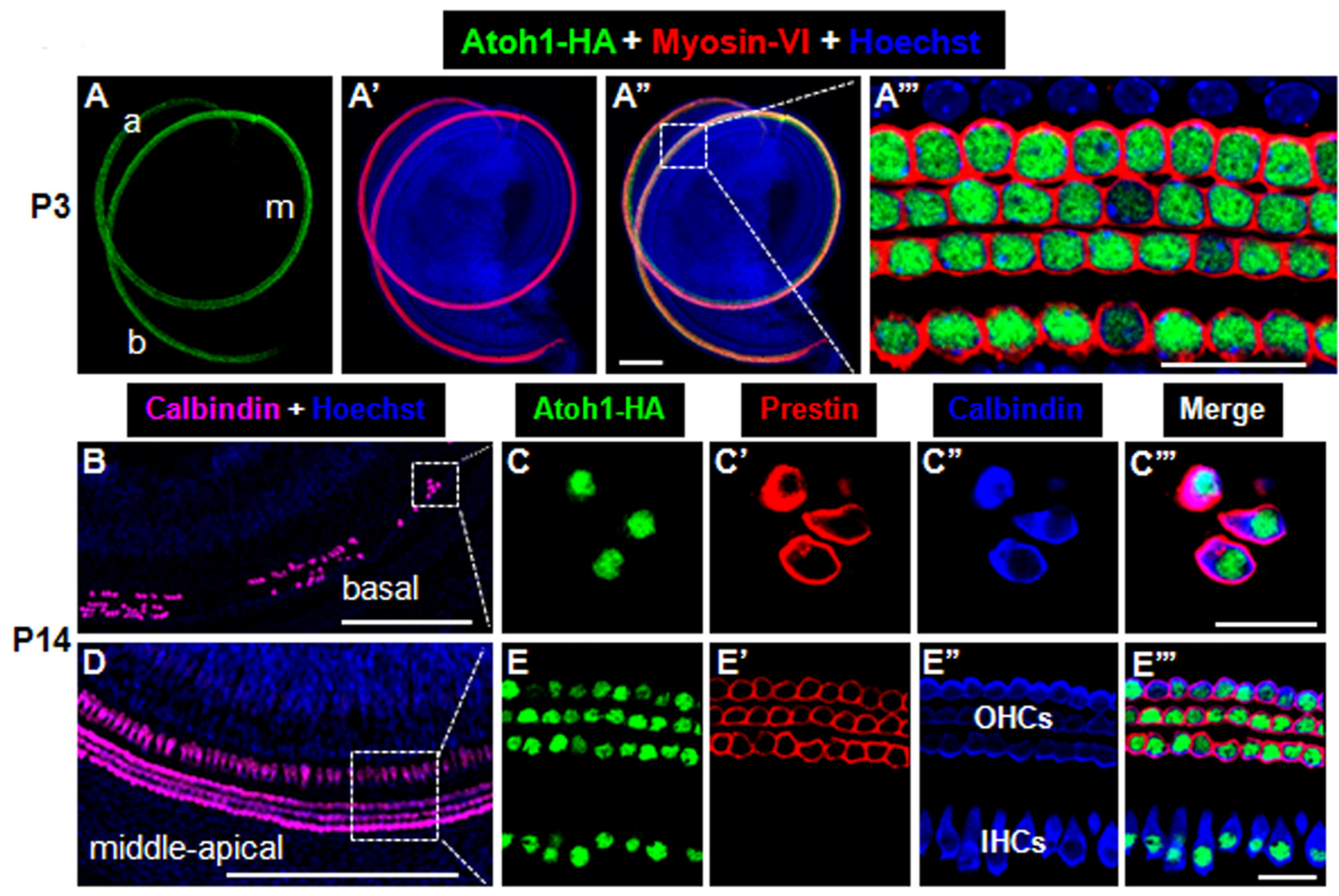

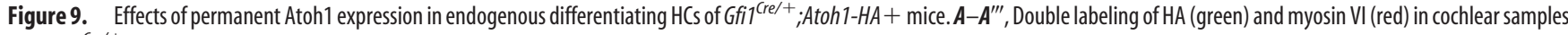
from $\mathrm{Gfi}^{\text {(re/+ }}{ }^{\text {; }}$ Atoh1-HA + mice at P3. All Atoh1-HA + HCs appeared normal. $\boldsymbol{B}-\boldsymbol{E}^{\prime \prime \prime}$, Triple labeling of HA (green), prestin (red), and calbindin (blue or pink) in the basal (B-C'") and middle/apical $\left(\boldsymbol{D}-\boldsymbol{E}^{\prime \prime \prime}\right)$ turns of the cochlea at P14. $\boldsymbol{B}$ and $\boldsymbol{D}$ are images showing calbindin channel alone. $\boldsymbol{C}^{\prime \prime}$ and $\mathbf{E}^{\prime \prime}$ are images showing calbindin in pseudo blue color. Many HCs are lost in the basal turn. a, Apical turn; $\mathrm{m}$, middle turn; b, basal turn. Scale bars, $200 \mu \mathrm{m}\left(\boldsymbol{A}^{\prime \prime}, \boldsymbol{B}, \boldsymbol{D}\right), 20 \mu \mathrm{m}\left(\boldsymbol{A}^{\prime \prime \prime}, \boldsymbol{C}^{\prime \prime}, \boldsymbol{E}^{\prime \prime \prime}\right)$.

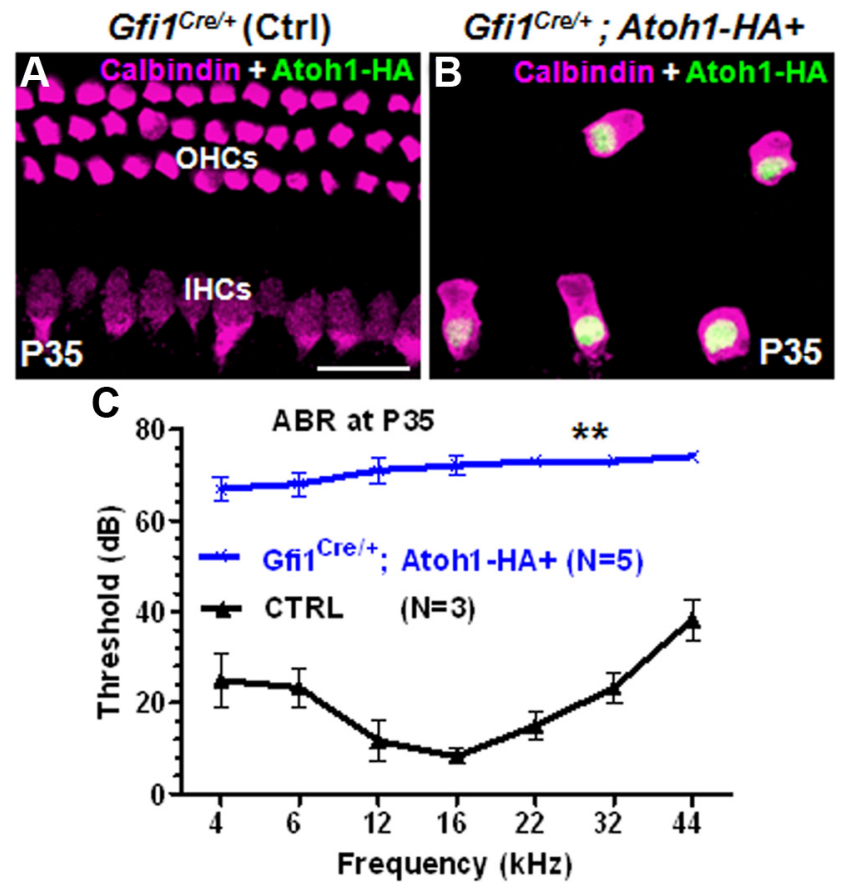

Figure 10. Loss of mature $\mathrm{HCs}$ in $\mathrm{Gfi}^{\left({ }^{\mathrm{Cr} /+}+\right.} ; A$ toh1-HA+ mice. $A, B$, Calbindin (pink) and $\mathrm{HA}$ (green) double staining in cochlear samples from control $(\boldsymbol{A})$ and experimental $(\boldsymbol{B})$ mice at P35 is shown. $\boldsymbol{C}$, Auditory brainstem response test comparing $\mathrm{Gfi}^{\left(\mathrm{Cre}^{+}+\right.} ;$Atoh1-HA+ (blue line) and $\mathrm{Gfi}^{\mathrm{Cre} /+}$ control (black line) mice. ${ }^{* *} p<0.01$ for all frequencies as determined by a two-way ANOVA followed by a Student's $t$ test with a Bonferroni correction. Scale bar, $20 \mu \mathrm{m}$. commitment and/or initial differentiation of immature HCs. Such a notion is further supported by our result that conversion of SCs into HCs recapitulates normal HC development, but new HCs remain immature in our models. In addition, the new HCs derived from GER cells by Atoh1 ectopic expression seem immature (Zheng and Gao, 2000). Does permanent ectopic Atoh1 expression cause the lack of prestin expression in our models? To test this, we permanently expressed Atoh1-HA in embryonic endogenous $\mathrm{HCs}$ in $\mathrm{Gfil}^{\mathrm{Cre} /+}$;Atoh1-HA+ mice and found that prestin was present in surviving OHCs at P14 (Fig. 9), which suggests that the absence of prestin in PC- and DC-derived new HCs was not caused by permanent Atoh1 expression. Instead, it is more likely that additional unknown transcription factors are needed for prestin expression and maturation of OHCs. Nonetheless, the significant HC loss in $\mathrm{Gfil}^{\mathrm{Cre} /+}$;Atoh1-HA+ mice suggests that permanent Atoh1-HA expression is detrimental to mature, adult HCs. Interestingly, PC- and DC-derived new HCs survived until adult ages, which is further evidence that these new HCs are immature since our data suggest that only adult, fully differentiated HCs are sensitive to permanent Atoh1 expression.

Converting one cell fate to another by overexpression of key transcriptional factors is a general and powerful approach for regenerative medicine (Cohen and Melton, 2011). SCs in nonmammalian vertebrates are the source for regenerating $\mathrm{HCs}$, and Atoh1 is reactivated in the process of $\mathrm{HC}$ regeneration (Cafaro et al., 2007). To endow mammals the capacity to regenerate HCs, similar to a recent study in the pancreas (Yang et al., 2011), we 
tested the effects of ectopic expression of a single transcription factor, Atoh1, in postnatal PCs and DCs. Our data suggest that Atoh1 can convert neonatal and juvenile, but not adult, PCs and DCs to adopt a HC fate, thus demonstrating that Atoh1mediated SC-to-HC conversion efficiency is age dependent. Moreover, newly generated HCs recapitulated the normal HC developmental program but failed to become fully differentiated. Thus, the combination of ectopic expression of Atoh1 and other factors that normally control HC terminal differentiation, especially those that can turn on prestin, may be valid approaches for the regeneration of fully differentiated, functional new HCs in vivo.

\section{References}

Avraham KB, Hasson T, Steel KP, Kingsley DM, Russell LB, Mooseker MS, Copeland NG, Jenkins NA (1995) The mouse Snell's waltzer deafness gene encodes an unconventional myosin required for structural integrity of inner ear hair cells. Nat Genet 11:369-375.

Ayrault O, Zhao H, Zindy F, Qu C, Sherr CJ, Roussel MF (2010) Atoh1 inhibits neuronal differentiation and collaborates with Glil to generate medulloblastoma-initiating cells. Cancer Res 70:5618-5627.

Bermingham NA, Hassan BA, Price SD, Vollrath MA, Ben-Arie N, Eatock RA, Bellen HJ, Lysakowski A, Zoghbi HY (1999) Math1: an essential gene for the generation of inner ear hair cells. Science 284:1837-1841.

Bermingham-McDonogh O, Oesterle EC, Stone JS, Hume CR, Huynh HM, Hayashi T (2006) Expression of Proxl during mouse cochlear development. J Comp Neurol 496:172-186.

Beurg M, Michalski N, Safieddine S, Bouleau Y, Schneggenburger R, Chapman ER, Petit C, Dulon D (2010) Control of exocytosis by synaptotagmins and otoferlin in auditory hair cells. J Neurosci 30:13281-13290.

Brigande JV, Heller S (2009) Quo vadis, hair cell regeneration? Nat Neurosci 12:679-685.

Buckiová D, Syka J (2009) Calbindin and S100 protein expression in the developing inner ear in mice. J Comp Neurol 513:469-482.

Cafaro J, Lee GS, Stone JS (2007) Atoh1 expression defines activated progenitors and differentiating hair cells during avian hair cell regeneration. Dev Dyn 236:156-170.

Chen P, Johnson JE, Zoghbi HY, Segil N (2002) The role of Math1 in inner ear development: uncoupling the establishment of the sensory primordium from hair cell fate determination. Development 129:2495-2505.

Chow LM, Tian Y, Weber T, Corbett M, Zuo J, Baker SJ (2006) Inducible Cre recombinase activity in mouse cerebellar granule cell precursors and inner ear hair cells. Dev Dyn 235:2991-2998.

Cohen DE, Melton D (2011) Turning straw into gold: directing cell fate for regenerative medicine. Nat Rev Genet 12:243-252.

Dechesne CJ, Rabejac D, Desmadryl G (1994) Development of calretinin immunoreactivity in the mouse inner ear. J Comp Neurol 346:517-529.

Du X, Jensen P, Goldowitz D, Hamre KM (2007) Wild-type cells rescue genotypically Math1-null hair cells in the inner ears of chimeric mice. Dev Biol 305:430-438.

Eybalin M, Renard N, Aure F, Safieddine S (2002) Cysteine-string protein in inner hair cells of the organ of Corti: synaptic expression and upregulation at the onset of hearing. Eur J Neurosci 15:1409-1420.

Fekete DM, Muthukumar S, Karagogeos D (1998) Hair cells and supporting cells share a common progenitor in the avian inner ear. J Neurosci 18:7811-7821.

Gubbels SP, Woessner DW, Mitchell JC, Ricci AJ, Brigande JV (2008) Functional auditory hair cells produced in the mammalian cochlea by in utero gene transfer. Nature 455:537-541.

Helms AW, Abney AL, Ben-Arie N, Zoghbi HY, Johnson JE (2000) Autoregulation and multiple enhancers control Mathl expression in the developing nervous system. Development 127:1185-1196.

Hertzano R, Dror AA, Montcouquiol M, Ahmed ZM, Ellsworth B, Camper S, Friedman TB, Kelley MW, Avraham KB (2007) Lhx3, a LIM domain transcription factor, is regulated by Pou $4 \mathrm{f} 3$ in the auditory but not in the vestibular system. Eur J Neurosci 25:999-1005.

Huang M, Sage C, Li H, Xiang M, Heller S, Chen ZY (2008) Diverse expres- sion patterns of LIM-homeodomain transcription factors (LIM-HDs) in mammalian inner ear development. Dev Dyn 237:3305-3312.

Hume CR, Bratt DL, Oesterle EC (2007) Expression of LHX3 and SOX2 during mouse inner ear development. Gene Expr Patterns 7:798-807.

Izumikawa M, Minoda R, Kawamoto K, Abrashkin KA, Swiderski DL, Dolan DF, Brough DE, Raphael Y (2005) Auditory hair cell replacement and hearing improvement by Atoh 1 gene therapy in deaf mammals. Nat Med 11:271-276.

Kubisch C, Schroeder BC, Friedrich T, Lütjohann B, El-Amraoui A, Marlin S, Petit C, Jentsch TJ (1999) KCNQ4, a novel potassium channel expressed in sensory outer hair cells, is mutated in dominant deafness. Cell 96:437-446.

Legendre K, Safieddine S, Küssel-Andermann P, Petit C, El-Amraoui A (2008) alphaII-betaV spectrin bridges the plasma membrane and cortical lattice in the lateral wall of the auditory outer hair cells. J Cell Sci 121:3347-3356.

Liu Z, Owen T, Zhang L, Zuo J (2010) Dynamic expression pattern of Sonic hedgehog in developing cochlear spiral ganglion neurons. Dev Dyn 239:1674-1683.

Liu Z, Owen T, Fang J, Srinivasan RS, Zuo J (2012) In vivo notch reactivation in differentiating cochlear hair cells induces sox 2 and prox 1 expression but does not disrupt hair cell maturation. Dev Dyn 241:684-696.

Madisen L, Zwingman TA, Sunkin SM, Oh SW, Zariwala HA, Gu H, Ng LL, Palmiter RD, Hawrylycz MJ, Jones AR, Lein ES, Zeng H (2010) A robust and high-throughput Cre reporting and characterization system for the whole mouse brain. Nat Neurosci 13:133-140.

Matei V, Pauley S, Kaing S, Rowitch D, Beisel KW, Morris K, Feng F, Jones $\mathrm{K}$, Lee J, Fritzsch B (2005) Smaller inner ear sensory epithelia in Neurog 1 null mice are related to earlier hair cell cycle exit. Dev Dyn 234:633-650

Meyers JR, MacDonald RB, Duggan A, Lenzi D, Standaert DG, Corwin JT, Corey DP (2003) Lighting up the senses: FM1-43 loading of sensory cells through nonselective ion channels. J Neurosci 23:4054-4065.

Mustapha M, Fang Q, Gong TW, Dolan DF, Raphael Y, Camper SA, Duncan RK (2009) Deafness and permanently reduced potassium channel gene expression and function in hypothyroid Pit1dw mutants. J Neurosci 29:1212-1223.

Nakamura T, Colbert MC, Robbins J (2006) Neural crest cells retain multipotential characteristics in the developing valves and label the cardiac conduction system. Circ Res 98:1547-1554.

Oesterle EC, Campbell S, Taylor RR, Forge A, Hume CR (2008) Sox2 and JAGGED1 expression in normal and drug-damaged adult mouse inner ear. J Assoc Res Otolaryngol 9:65-89.

Pan N, Jahan I, Kersigo J, Kopecky B, Santi P, Johnson S, Schmitz H, Fritzsch B (2011) Conditional deletion of Atoh1 using Pax2-Cre results in viable mice without differentiated cochlear hair cells that have lost most of the organ of Corti. Hear Res 275:66-80.

Pan N, Jahan I, Kersigo J, Duncan JS, Kopecky B, Fritzsch B (2012) A novel atoh1 "self-terminating" mouse model reveals the necessity of proper atoh1 level and duration for hair cell differentiation and viability. PLoS One 7:e30358.

Rivers LE, Young KM, Rizzi M, Jamen F, Psachoulia K, Wade A, Kessaris N, Richardson WD (2008) PDGFRA/NG2 glia generate myelinating oligodendrocytes and piriform projection neurons in adult mice. Nat Neurosci 11:1392-1401.

Simmons DD, Tong B, Schrader AD, Hornak AJ (2010) Oncomodulin identifies different hair cell types in the mammalian inner ear. J Comp Neurol 518:3785-3802.

Srinivasan RS, Dillard ME, Lagutin OV, Lin FJ, Tsai S, Tsai MJ, Samokhvalov IM, Oliver G (2007) Lineage tracing demonstrates the venous origin of the mammalian lymphatic vasculature. Genes Dev 21:2422-2432.

Stone JS, Cotanche DA (2007) Hair cell regeneration in the avian auditory epithelium. Int J Dev Biol 51:633-647.

Szabo E, Rampalli S, Risueño RM, Schnerch A, Mitchell R, Fiebig-Comyn A, Levadoux-Martin M, Bhatia M (2010) Direct conversion of human fibroblasts to multilineage blood progenitors. Nature 468:521-526.

Utomo AR, Nikitin AY, Lee WH (1999) Temporal, spatial, and cell typespecific control of Cre-mediated DNA recombination in transgenic mice. Nat Biotechnol 17:1091-1096. 
Woods C, Montcouquiol M, Kelley MW (2004) Math1 regulates development of the sensory epithelium in the mammalian cochlea. Nat Neurosci $7: 1310-1318$

Xie H, Ye M, Feng R, Graf T (2004) Stepwise reprogramming of B cells into macrophages. Cell 117:663-676.

Yang H, Gan J, Xie X, Deng M, Feng L, Chen X, Gao Z, Gan L (2010a) Gfil-Cre knock-in mouse line: a tool for inner ear hair cell-specific gene deletion. Genesis 48:400-406.

Yang H, Xie X, Deng M, Chen X, Gan L (2010b) Generation and characterization of Atoh1-Cre knock-in mouse line. Genesis 48:407-413.

Yang YP, Thorel F, Boyer DF, Herrera PL, Wright CV (2011) Contextspecific $\alpha$-to- $\beta$-cell reprogramming by forced Pdx1 expression. Genes Dev 25:1680-1685.

Young KM, Mitsumori T, Pringle N, Grist M, Kessaris N, Richardson WD
(2010) An Fgfr3-iCreER(T2) transgenic mouse line for studies of neural stem cells and astrocytes. Glia 58:943-953.

Yu Y, Weber T, Yamashita T, Liu Z, Valentine MB, Cox BC, Zuo J (2010) In vivo proliferation of postmitotic cochlear supporting cells by acute ablation of the retinoblastoma protein in neonatal mice. J Neurosci 30:5927-5936.

Zheng JL, Gao WQ (2000) Overexpression of Math1 induces robust production of extra hair cells in postnatal rat inner ears. Nat Neurosci 3:580-586.

Zhou Q, Brown J, Kanarek A, Rajagopal J, Melton DA (2008) In vivo reprogramming of adult pancreatic exocrine cells to beta-cells. Nature 455:627-632.

Zuo J, Treadaway J, Buckner TW, Fritzsch B (1999) Visualization of alpha9 acetylcholine receptor expression in hair cells of transgenic mice containing a modified bacterial artificial chromosome. Proc Natl Acad Sci U S A 96:14100-14105. 